\title{
Ion Mobility Spectrometry-Hydrogen Deuterium Exchange Mass Spectrometry of Anions: Part 1. Peptides to Proteins
}

\author{
Gregory C. Donohoe, Mahdiar Khakinejad, Stephen J. Valentine \\ C. Eugene Bennett Department of Chemistry, West Virginia University, Morgantown, WV 26506, USA
}

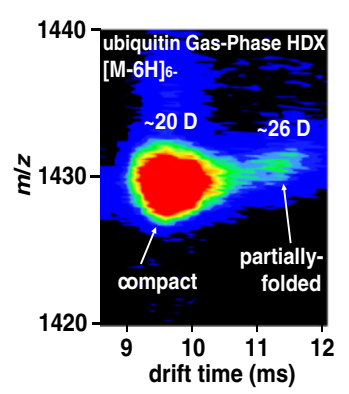

\begin{abstract}
Ion mobility spectrometry (IMS) coupled with hydrogen deuterium exchange (HDX)-mass spectrometry (MS) has been used to study the conformations of negatively-charged peptide and protein ions. Results are presented for ion conformers of angiotensin 1, a synthetic peptide (SP), bovine insulin, ubiquitin, and equine cytochrome $c$. In general, the SP ion conformers demonstrate a greater level of HDX efficiency as a greater proportion of the sites undergo HDX. Additionally, these ions exhibit the fastest rates of exchange. Comparatively, the angiotensin 1 ions exhibit a lower rate of exchange and HDX level presumably because of decreased accessibility of exchange sites by charge sites. The latter are likely confined to the peptide termini. Insulin ions show dramatically reduced HDX levels and
\end{abstract} exchange rates, which can be attributed to decreased conformational flexibility resulting from the disulfide bonds. For the larger ubiquitin and protein ions, increased HDX is observed for larger ions of higher charge state. For ubiquitin, a conformational transition from compact to more elongated species (from lower to higher charge states) is reflected by an increase in HDX levels. These results can be explained by a combination of interior site protection by compact conformers as well as decreased access by charge sites. The elongated cytochrome $c$ ions provide the largest HDX levels where higher values correlate with charge state. These results are consistent with increased exchange site accessibility by additional charge sites. The data from these enhanced IMS-HDX experiments are described in terms of charge site location, conformer rigidity, and interior site protection.

Keywords: Ion mobility spectrometry, Hydrogen deuterium exchange, Protein anions

Received: 19 August 2014/Revised: 28 October 2014/Accepted: 28 October 2014/Published Online: 16 December 2014

\section{Introduction}

$\mathrm{T}$ he development of soft ionization methods such as electrospray ionization (ESI) [1] and matrix-assisted laser desorption (MALDI) [2, 3] presented the unique opportunity to study the gas-phase conformations of large biomolecular ions. Within a short time, a variety of mass spectrometry (MS)-based techniques were developed for the structural characterization of these ions as well as to relate gas-phase conformers to antecedent solution structures [4-20]. One early technique determined the gas-phase hydrogen-deuterium exchange (HDX) reactivities of ions comprising different charge states of proteins [6, 21-24]. The observation of different HDX rates and maximum HDX levels indicated the presence of coexisting gas-phase

Gregory C. Donohoe and Mahdiar Khakinejad contributed equally to this work.

Correspondence to: Stephen Valentine; e-mail: stephen.valentine@ mail.wvu.edu conformations [6]. Early theoretical studies resulted in proposed mechanisms for HDX of protonated peptide ions by a number of deuterating agents $[8,22]$.

Concurrent to the development of HDX techniques, experimental efforts were directed at utilizing ion mobility spectrometry (IMS) coupled with MS for the determination of collision cross-sections for peptide and protein ions [9, 19, 20, 25]. Shortly thereafter, IMS-MS was combined with HDX in order to determine the reactivities of specific gas-phase conformers of peptide and protein ions [23, 26, 27]. Initial studies [26] reported the maximum HDX levels as well as rates of exchange for a number of cytochrome $c$ ion conformers. These early studies demonstrated that compact cytochrome $c$ ion conformers exhibited decreased levels of HDX compared with more elongated ions. Additionally, the overall HDX levels were compared with those reported for the same ion charge states as measured in a Fourier transform ion cyclotron resonance (FTICR) mass spectrometer [6]. In general, the HDX levels recorded for the mobility-resolved conformers was 
determined to be smaller than that recorded for ions in the FTICR. This was explained as possibly arising from the longer timescale of the latter measurement rendering the observed exchange process subject to longer timescale structural fluctuations. An alternate explanation was that the two instruments sampled different ion conformers.

The initial IMS-HDX-MS studies of cytochrome $c$ conformers were followed with temperature-dependent experiments [27] in which the exchange levels of elongated and compact ion conformers were examined across a temperature range of 300 to $>400 \mathrm{~K}$. In general, both conformers exchanged a greater number of hydrogens at higher temperatures. However, at low temperatures, compact cytochrome $c$ ion conformers were observed to protect a number of hydrogens compared with more elongated conformers while at higher temperatures $(>400 \mathrm{~K})$, the opposite behavior was observed. That is, here elongated protein ions were observed to protect a greater number of hydrogens from exchange. The IMS-HDXMS results were combined with molecular dynamics simulations to demonstrate protection of exchange sites for the more diffuse gas-phase conformations of higher charge [27]. This work suggested that at higher temperatures, the increased conformational fluctuations for the compact ions were more efficient at positioning a greater number of exchange sites in proximity to charge sites rendering them accessible for exchange via the proposed relay mechanism $[8,23]$.

Although the early IMS-HDX-MS experiments provided information about the degree of protection afforded by the protein fold associated with elongated and compact conformations, no information regarding the residue location of deuterium incorporation was obtainable. The advent of nonergodic ion dissociation techniques such as electron capture dissociation (ECD) [28] and electron transfer dissociation (ETD) [29] brought renewed interest in gas-phase HDX as it became possible to locate exchange sites based on MS/MS information [30-32]. One study involved the use of a traveling wave ion guide (TWIG) ion mobility characterization of protein ions in which MS/MS experiments utilizing ETD revealed protected and accessible sites [33]. However, with these types of analyses, a question arises as to the temperature of the ions in the TWIG device and its effect on deuterium incorporation [34, 35]. Because temperature-dependent IMS-HDX-MS experiments have shown changes in maximum HDX levels and rates of exchange [27], such analyses should be treated cautiously. More recently, drift tube IMS-HDX-MS/MS experiments provided site-specific deuterium incorporation information for separate peptide ion conformers [36].

Although the gas-phase HDX characteristics of negatively charged oligonucleotides and small molecules including amino acids have been studied [37-42], HDX of protein and peptide anions has received considerably less attention [43]. As a consequence, no experiments describing systematic HDX characterization of peptide and protein anions exists. Because many proteins contain a large number of acidic residues, it is useful to develop a sound understanding of the conformational information afforded by gas-phase HDX measurements for select conformers from negatively-charged protein ions. Moreover, the degree of HDX scrambling occurring for activated, negatively-charged peptide ions has recently been reported [44]. Such information begins to lay the foundation for an understanding of intramolecular deuterium migration, which can further clarify the type of structural information that can be obtained from HDX experiments. Additionally, recent pivotal experiments have compared the charge states and structures of proteins and protein complex anions with cationic species providing evidence for a charge-carrier emission process occurring at late stages of the electrospray process [45]. Similarly, the combined IMS-HDX-MS studies described here present novel experiments in which the first conformer-specific analyses of peptide and protein anions have been conducted. That said, the methods utilized in these studies are similar to those employed previously for the characterization of conformers of positively-charged peptide and protein ions [23, 26, 27, 36]. Finally, it should be noted that with the rapid development of novel ion fragmentation techniques [28, 29, 46-51], the experiments described here are timely; that is, this work leads to future studies allowing the determination of residue-specific deuterium uptake for select anion conformers [36].

As a general comparison of the biomolecules examined here, the small peptides exhibit HDX differences that can be accounted for when considering charge site location; the larger peptide ions for which one or more charge sites are located on interior residues display increased levels of exchange. Additionally, for the larger peptide, maximum HDX levels are not observed to increase as charge state increases. In contrast, maximum HDX levels are observed to increase with higher charge states for the larger protein ions. This dissimilarity may be explained by the increased charge density of the former ions, which may impose increased conformational rigidity thereby decreasing access to exchange sites as suggested in positive ion studies [36]. The ion conformers produced by ESI of bovine insulin are observed to exchange the fewest hydrogens and exhibit the slowest rates of exchange. Finally, multimeric peptide ions show a level of protection from $[2 \mathrm{M}-3 \mathrm{H}]^{3-}$ to $[3 \mathrm{M}-$ $4 \mathrm{H}]^{4-}$ ions. These data are discussed while considering a charge-mediated HDX process and various conformational constraints on that process.

\section{Experimental}

\section{Sample Preparation}

Samples were selected to allow comparisons of a variety of gas-phase ion conformers, including those formed from two small peptides, a conformationally-restricted protein (disulfide bonds), and globular proteins of increasing size. The peptides were selected to investigate the HDX properties of ion conformers for which charges were located on the interior of the peptide compared with a model where the charges were located at the peptide termini. The peptide angiotensin 1 (DRVYIHPFHL) was purchased (95\%; Fisher Scientific, Fair Lawn, NJ, USA) and used without further purification. 
The synthetic peptide (hereafter referred to as SP) KKDDDDDIIKIIK was purchased (90\%; Genscript Corp., Piscataway, NJ, USA) and used without further purification. The proteins bovine insulin (90\%), ubiquitin $(95 \%)$, and equine cytochrome $c(95 \%)$ were purchased (Sigma Aldrich, St. Louis, MO, USA) and used without further purification. Ultra-pure (chromatography grade) deionized water, acetonitrile, and ammonium hydroxide (Fisher Scientific, Fair Lawn, NJ, USA) were used to generate stock and ESI solutions of the peptide and proteins. The stock solutions were prepared by dissolving $1.0 \mathrm{mg}$ of analyte in $1.0 \mathrm{~mL}$ of ultrapure water and were capped in glass vials while being maintained in a refrigerator $\left(4^{\circ} \mathrm{C}\right)$; no stock solution was used a week after preparation. ESI solutions $\left(0.1 \mathrm{mg} \cdot \mathrm{mL}^{-1}\right)$ were prepared fresh by diluting $0.1 \mathrm{~mL}$ of stock solution with the addition of $0.4 \mathrm{~mL}$ of ammonium hydroxide and 0.5 $\mathrm{mL}$ of acetonitrile. Samples were infused through a pulledtip capillary using a flow rate of $300 \mathrm{~nL} \cdot \mathrm{min}^{-1}$.

\section{Ion Mobility Measurements}

The use of ion mobility spectrometry for the characterization of biomolecules has an extensive history; the development of IMS instrumentation [9, 19, 25, 52-67], theory [68-79], and applications [80-84] have been discussed in detail. The IMS-MS instrument used in these studies has also been described previously $[36,85]$. A brief description of the instrument and data collection and analysis is presented here. Figure 1 shows a schematic of the drift tube, linear ion trap instrument used to conduct these experiments. Peptide/protein ions are generated by electrospraying the ESI solution through a pulled-tip capillary. The capillary is biased at approximately $-2200 \mathrm{~V}$ above the entrance aperture of the desolvation region (Figure 1). Here ions are desolvated and focused into an "hour-glass" ion funnel [86] (F1/IA1/G1 in Figure 1). Ions are trapped near the exit region of the ion funnel and periodically (typically $50 \mathrm{~Hz}$ ) pulsed into the drift tube. The drift tube is filled with He buffer gas $(300 \mathrm{~K})$ and supports a drift field of $\sim 10 \mathrm{~V} \cdot \mathrm{cm}^{-1}$. Ions separate in the drift tube based on differences in their mobilities through the buffer gas. The second ion gate (G2 in Figure 1) is employed to select ions of specific mobilities for transmission into the LTQ Velos linear ion trap (ThermoScientific, San Jose, CA, USA) for mass analysis.
Delay times between the high-voltage pulse applied to the drift tube entrance gate (G1) and the mobility selection gate (G2) are scanned in order to generate IMS-MS datasets. In the current instrument, G1 is a single gridded lens and G2 is a Tyndall gate located directly in front of the second ion funnel. G1 prevents ions from entering the drift tube using an $\sim 40 \mathrm{~V}$ bias relative to first ion funnel exit. Periodically, a $150 \mu$ s-long voltage pulse is applied to G1 to allow ions to enter the drift tube. The Tyndall gate, with a bias of $\sim 10 \mathrm{~V}$, neutralizes all ions with the exception of those selected for transmission by the time delay of the voltage pulse applied to G2 relative to G1. The timing of G1 and G2 is synchronized by two four-channel digital/delay pulse generators (Stanford Research Systems, Sunnyvale, CA, USA). Drift time $\left(t_{D}\right)$ delays are scanned from $\sim 3 \mathrm{~ms}$ to $\sim 15 \mathrm{~ms}$ (200 $\mu$ s increments) to encompass the entire $t_{D}$ range of all ions produced by ESI.

\section{Mass Spectrometry Measurements}

Total ion mass spectra are generated by setting the drift tube gates to pass all ions. In this operational mode, all ions pass into the mass analyzer. The mass analyzer scan parameters include a $\mathrm{m} / \mathrm{z}$ range of 80 to 2000 as well as automatic gain control (AGC) with a threshold of $1 \times 10^{6}$ ions. For these analyses, sample injection times of $200 \mathrm{~ms}$ (five microscans) have been utilized. During $t_{D}$ distribution generation, the ion gates in the drift tube are activated as mentioned above to transmit ions of a specific mobility into the linear trap. Data acquisition is accomplished by collecting a mass spectrum $(0.5 \mathrm{~min})$ for each $t_{D}$ selection setting. For IMS data generation, the AGC is disabled and a sample injection time of $200 \mathrm{~ms}$ (five microscans) is also employed.

\section{Generation of IMS-MS Datasets and XIDTDs}

To generate the two-dimensional IMS-MS dataset, each $t_{D}$ selected mass spectrum (.RAW file) is converted to a separate text file. All $\mathrm{x}$ and y data points ( $\mathrm{m} / \mathrm{z}$ values and intensities) are then associated with the respective mobility selection time $\left(t_{D}\right)$ using software developed in-house. This process creates a three-column array text file containing $t_{D}, \mathrm{~m} / \mathrm{z}$, and intensity values. Intensity filters can be applied to control the size of the three-column array file. To generate $t_{D}$ distributions for ions of

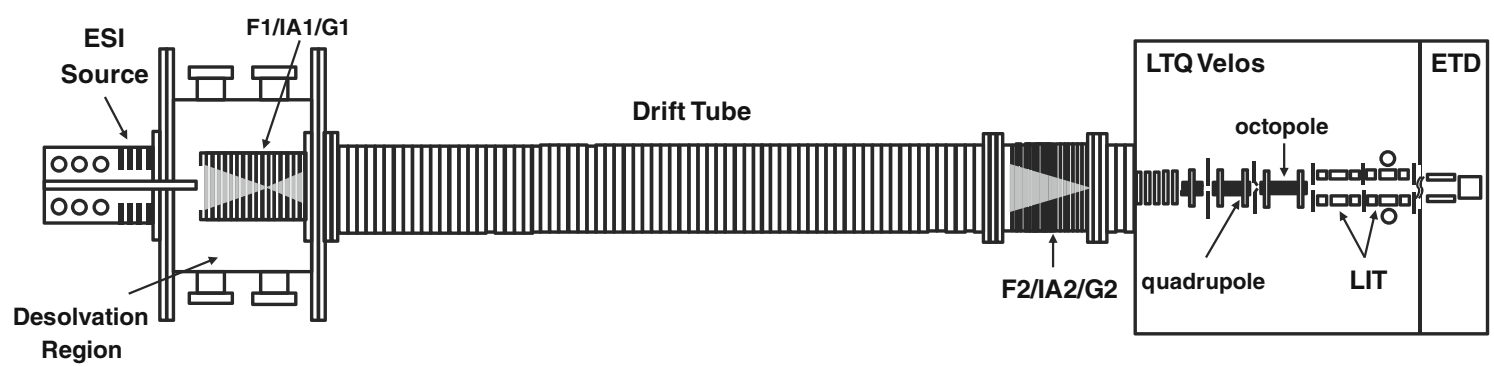

Figure 1. Schematic of the instrument used in the IMS-HDX experiments. Ion funnels (F), ion gates (G), and ion activation regions (IA) are shown in the diagram. The LTQ Velos linear ion trap with the ETD ion source is also labeled 
specific $\mathrm{m} / \mathrm{z}$ values, a separate program developed in-house integrates all intensities within a user-defined $\mathrm{m} / \mathrm{z}$ range for each $t_{D}$. In accordance with previous studies, this is called an extracted ion drift time distribution (XIDTD) [87].

\section{HDX Experiments}

Gas-phase HDX is accomplished by introducing $\mathrm{D}_{2} \mathrm{O}(>99 \%$; Sigma Aldrich, St. Louis, MO, USA) into the drift tube buffer gas system. First, the $\mathrm{D}_{2} \mathrm{O}$ was purified by several freezing and melting cycles under vacuum. The partial pressures of $\mathrm{D}_{2} \mathrm{O}$ and helium are adjusted with two separate leak valves, (Granville Philips, Longmont, CO, USA) and monitored using a Baratron capacitance manometer (MKS, Andover, MA, USA). For these experiments, the helium partial pressure is set at $2.50 \pm 0.01$ Torr. The partial pressure of $\mathrm{D}_{2} \mathrm{O}$ is varied from $\sim 0.005$ to $\sim 0.20$ Torr. $t_{D}$ Distributions are first recorded in pure He to allow the determination of accurate collision cross-sections. To ensure no conformational transitions occur, the $t_{D}$ distributions are monitored upon adding $\mathrm{D}_{2} \mathrm{O}$ as demonstrated previously [26]. Additionally, the $\mathrm{D}_{2} \mathrm{O}$ uptake for the different ions is recorded at different $\mathrm{D}_{2} \mathrm{O}$ partial pressures. The partial pressures of the components of the buffer gas system are stable, differing by less than \pm 0.005 Torr during the course of the mass spectral characterization as well and upon removal of the $\mathrm{D}_{2} \mathrm{O}$, and the total pressure quickly re-equilibrates to 2.50 Torr.

\section{HDX Levels and Rate Constants}

The number of deuteriums incorporated into specific ion conformers is determined by subtracting their average $\mathrm{m} / \mathrm{z}$ value after passing through the pure He buffer gas from their average $m / z$ value after passing through a $\mathrm{He} / \mathrm{D}_{2} \mathrm{O}$ mixture. Average values are determined using a simple algorithm developed inhouse that weights each $\mathrm{m} / \mathrm{z}$ point in the isotopic distribution by its intensity.

HDX rate constants have been determined for a number of different ion conformers assuming pseudo first order kinetics as described previously $[6,21,26,27]$. Briefly, the partial pressure of $\mathrm{D}_{2} \mathrm{O}$ is adjusted in small increments (as little as 0.01 Torr) from 0 to 0.20 Torr and the $t_{D} \mathrm{~S}$ and HDX levels of different ion conformers are determined. A semi-log plot of the number of remaining exchangeable hydrogens as a function of the product of the $\mathrm{D}_{2} \mathrm{O}$ partial pressure and $t_{D}$ provides a means for determining the rate constant; the slopes of best linear fits to the data on the semi-log plot are used for this determination.

\section{Results and Discussion}

\section{Peptide and Protein Ion Collision Cross- Sections}

Figure 2a shows the two-dimensional $t_{D}, m / z$ distribution obtained for negatively-charged ubiquitin ions. Ions produced from the ubiquitin sample range from the $[\mathrm{M}-5 \mathrm{H}]^{5-}$ to the $[\mathrm{M}-9 \mathrm{H}]^{9-}$ species. The drift times for these same ions range from $\sim 7.5$ to $13 \mathrm{~ms}$. The data indicate a transition from a more elongated structural conformation type to a more compact structural type for the $[\mathrm{M}-7 \mathrm{H}]^{7-}$ and $[\mathrm{M}-6]^{6-}$ ions, respectively. This is evidenced by the higher mobility of the dominant conformer type for the latter ions (shorter $t_{D}$ in Figure 2a). Ion elongation resulting from increased Coulomb repulsion has been described for a number of protonated and deprotonated protein ions [81, 88-90]. Figure $2 \mathrm{~b}$ shows the $t_{D}, m / z$ distribution obtained for negatively-charged ubiquitin ions upon addition of $\sim 0.04$ Torr of $\mathrm{D}_{2} \mathrm{O}$ into the drift tube buffer gas. In general, the $\mathrm{m} / \mathrm{z}$ peaks become broader because of the incorporation of deuteriums at heteroatom exchange sites. On average, the $t_{D}$ values of ion conformers increase by $\sim 0.5 \mathrm{~ms}$. At this $\mathrm{D}_{2} \mathrm{O}$ partial pressure, it is expected that the more accessible exchange sites (exhibiting more rapid exchange) have incorporated deuteriums (see HDX kinetics discussion below). Although the addition of $\mathrm{D}_{2} \mathrm{O}$ does not appear to alter the conformations of the observed ions as evidenced by the similar $t_{D}$ distributions, at higher $\mathrm{D}_{2} \mathrm{O}$ partial pressures, the overall ion signal level decreases and maximum HDX levels and rate constants cannot be determined for some ion conformers of lower abundance.

Collision cross-sections for the features in the $t_{D}$ separations have been determined for all ions of the different samples using the expression [71]:

$\Omega=\frac{(18 \pi)^{1 / 2}}{16} \frac{\boldsymbol{z} \boldsymbol{e}}{\left(\boldsymbol{k}_{B} \boldsymbol{T}\right)^{1 / 2}}\left[\frac{1}{\boldsymbol{m}_{\boldsymbol{I}}}+\frac{1}{\boldsymbol{m}_{B}}\right]^{1 / 2} \frac{\boldsymbol{t}_{\boldsymbol{D}} \boldsymbol{E}}{\boldsymbol{L}} \frac{760}{\boldsymbol{P}} \frac{\boldsymbol{T}}{273.2} \frac{1}{\boldsymbol{N}}$

In Equation (1), ze and $k_{B}$ correspond to the charge of the ion and Boltzmann's constant, respectively. The variables $m_{I}$ and $m_{B}$ correspond to the mass of the ion and the mass of the buffer gas, respectively. $E, L, T$, and $P$ correspond to the electric field, length of the drift tube, and the temperature and pressure of the buffer gas, respectively. $N$ represents the neutral number density at standard temperature and pressure (STP) conditions.

The collision cross-sections of ions produced by the smaller ions (angiotensin 1, SP, and bovine insulin) are shown in Figure $3 \mathrm{a}$ and are listed in Table 1. For illustrative purposes, the collision cross-sections of ions from these smaller molecules are depicted separately from those formed by the larger proteins (ubiquitin and cytochrome $c$ ). For all monomeric ions produced by the smaller molecules (Figure 3a), collision crosssections range from 275 to $808 \AA^{2}$ for the $[\mathrm{M}-2 \mathrm{H}]^{2-}$ ions of the angiotensin 1 peptide to $[\mathrm{M}-5 \mathrm{H}]^{5-}$ ions of bovine insulin, respectively. Figure 3 a shows that collision cross-section distributions indicate that several $[\mathrm{M}-\mathrm{nH}]^{\mathrm{n}-}$ ions yield two conformations (i.e., two features are observed in the $t_{D}$ distribution). These collision cross-sections are also summarized in Table 1. For the small molecules, the observed multimeric ions yield single features in the $t_{D}$ distributions. SP is observed to form three detectable multimers having cross-sections of 518,705 , and $881 \AA^{2}$ for the $[2 \mathrm{M}-3 \mathrm{H}]^{3-},[3 \mathrm{M}-4 \mathrm{H}]^{4-}$, and $[4 \mathrm{M}-5 \mathrm{H}]^{5-}$ ions, respectively, whereas insulin is observed to produce a single ion, $[2 \mathrm{M}-7 \mathrm{H}]^{7-}$, having a relatively larger cross-section of $1260 \AA^{2}$. 

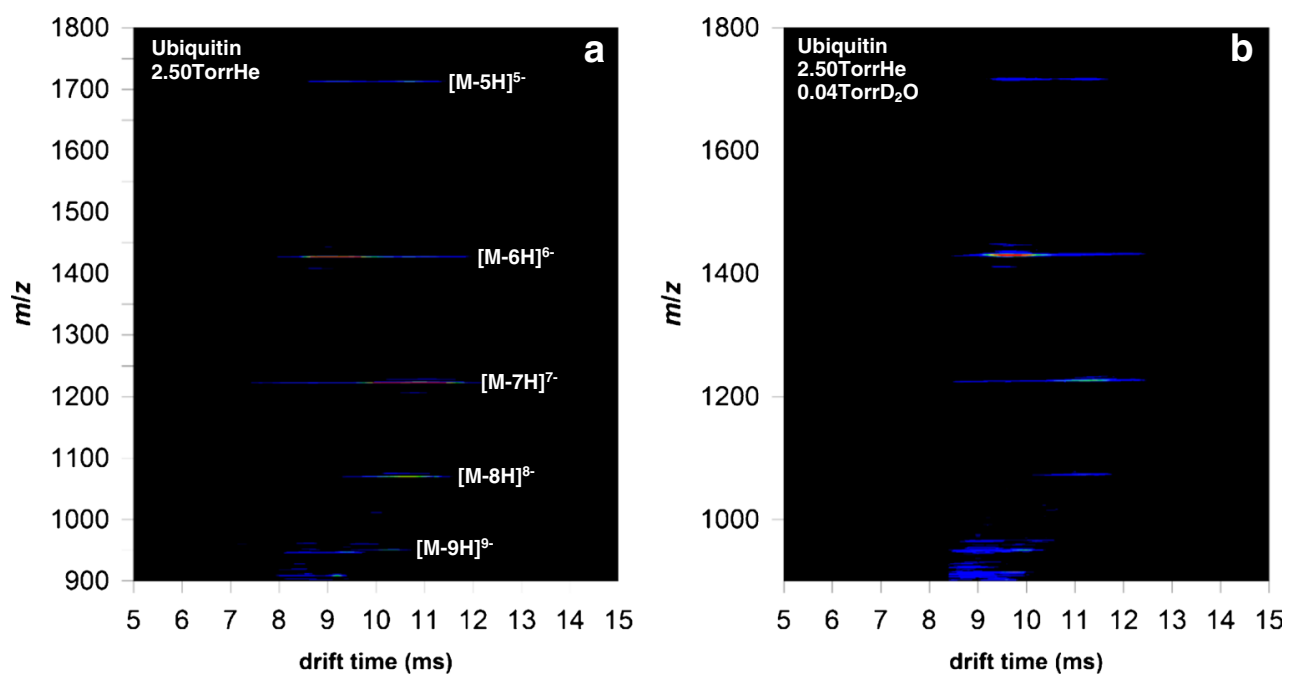

Figure 2. (a) Two-dimensional $t_{D}, \mathrm{~m} / \mathrm{z}$ contour plot of electrosprayed ubiquitin ions using 2.5 Torr He buffer gas in the drift tube. (b) Two-dimensional $t_{D}, m / z$ contour plot of electrosprayed ubiquitin ions using a He: $\mathrm{D}_{2} \mathrm{O}(2.5: 0.04$ Torr) buffer gas mixture in the drift tube. The intensity is represented with a color scale using linear cutoff thresholds. The maximum intensity cutoff is 50 and 6 ion counts for panels $a$ and $b$, respectively. The ions of different charge are labeled on the plot in panel a

It is instructive to consider the relative sizes of the multimeric species. Notably, the $[2 \mathrm{M}-3 \mathrm{H}]^{3-},[3 \mathrm{M}-4 \mathrm{H}]^{4-}$, and $[4 \mathrm{M}-5 \mathrm{H}]^{5-}$ ions from the SP peptide exhibit collision cross-sections that are near the same size as the same charge states of the monomeric insulin ions. This observation is interesting considering that the bovine insulin molecules contain approximately four times more amino acid residues. Thus, in comparison, the dimer ions of SP and the monomer ions of bovine insulin of the same charge are relatively large and small, respectively. Even the trimer ions of SP would be considered to be relatively large compared with the bovine insulin ions of the same charge. It is suggested that the largest contributing factor to the relatively smaller size of the insulin ions is the presence of the four disulfide bonds, which serve to tether the molecule in more compact conformations even at higher charge states. This phenomenon has been described previously [90].

The collision cross-sections for the ions formed from the larger proteins are shown in Figure $3 \mathrm{~b}$. For these ions, crosssections range in size from 862 to $2713 \AA^{2}$, corresponding to $[\mathrm{M}-5 \mathrm{H}]^{5-}$ ubiquitin and $[\mathrm{M}-14 \mathrm{H}]^{14-}$ cytochrome $c$ ions, respectively. Ubiquitin ions show both compact and more elongated conformations across the observed charge state distribution. A transition from the dominant species comprised of more compact ions to more elongated ions is observed from the $[\mathrm{M}-6 \mathrm{H}]^{6-}$ to the $[\mathrm{M}-7 \mathrm{H}]^{7-}$ species as evidenced in Figure 2 (see discussion above). The dataset features observed for cytochrome $c$ show only single conformer types across the charge state range from the $[\mathrm{M}-7 \mathrm{H}]^{7-}$ to the $[\mathrm{M}-14 \mathrm{H}]^{14-}$ ions. The overlapping charge states for cytochrome $c$ and ubiquitin roughly reflect the difference in size of the two proteins. That is, cytochrome $c$ contains $\sim 37 \%$ more amino acid residues than ubiquitin. Additionally, no compact ions are observed for these charge states of cytochrome $c$. The collision cross-sections of the elongated cytochrome $c$ protein ions have been compared with values reported in an online database [91] obtained from separate IMS measurements, and the average percent difference is determined to be $1.7 \% \pm 0.3 \%$.

\section{Gas-Phase Deuterium Uptake as a Function of $\mathrm{D}_{2} \mathrm{O}$ Pressure}

The addition of $\mathrm{D}_{2} \mathrm{O}$ to the drift tube results in shifts of the $\mathrm{m} / \mathrm{z}$ values of the various ions to higher values, indicating the incorporation of deuterium. Figure 4a shows the increase in $\mathrm{m} / \mathrm{z}$ of the more compact conformer of $[\mathrm{M}-5 \mathrm{H}]^{5-}$ ubiquitin ions as a function of the product of ion $t_{D}$ and partial pressure of $\mathrm{D}_{2} \mathrm{O}$. Initially, small increases in $\mathrm{D}_{2} \mathrm{O}$ partial pressure are associated with large increases in HDX levels, whereas at higher $\mathrm{D}_{2} \mathrm{O}$ partial pressures the HDX level reaches a near maximum value corresponding to uptake of $\sim 28$ deuteriums. Using this deuterium uptake data, it is possible to generate a semilog plot of the remaining hydrogens as a function of the product of $\mathrm{D}_{2} \mathrm{O}$ partial pressure and ion residence time in the drift tube as shown in Figure 4b. A linear relation for the first three to four data points is observed; however, beyond this point, the data deviate from linearity. The observation of a linear region for the uptake of the first deuteriums has been observed in studies of positively-charged protein ions and has been ascribed to fast-exchanging sites near the charge sites [26, 27]. Using a linear fit to the first data points (Figure $4 \mathrm{~b}$ ) allows the estimation of an HDX rate constant for the fast-exchanging sites. For the $[\mathrm{M}-5 \mathrm{H}]^{5-}$ ions, this rate constant is determined to be $1.3 \times 10^{-13} \mathrm{~cm}^{3} \cdot \mathrm{s}^{-1} \cdot \mathrm{molecule}^{-1}$. The data in Figure $4 \mathrm{~b}$ also suggest that some hydrogens exchange at a slower rate. Using the remaining data points up to those representing complete exchange, a second linear correlation provides a slower rate constant of $6.5 \times 10^{-14} \mathrm{~cm}^{3} \cdot \mathrm{s}^{-1} \cdot$ molecule ${ }^{-1}$.

The maximum HDX levels and rate constants for all dominant ion conformations are listed in Table 1 . For many conformations, both faster- and slower-exchanging hydrogens can 

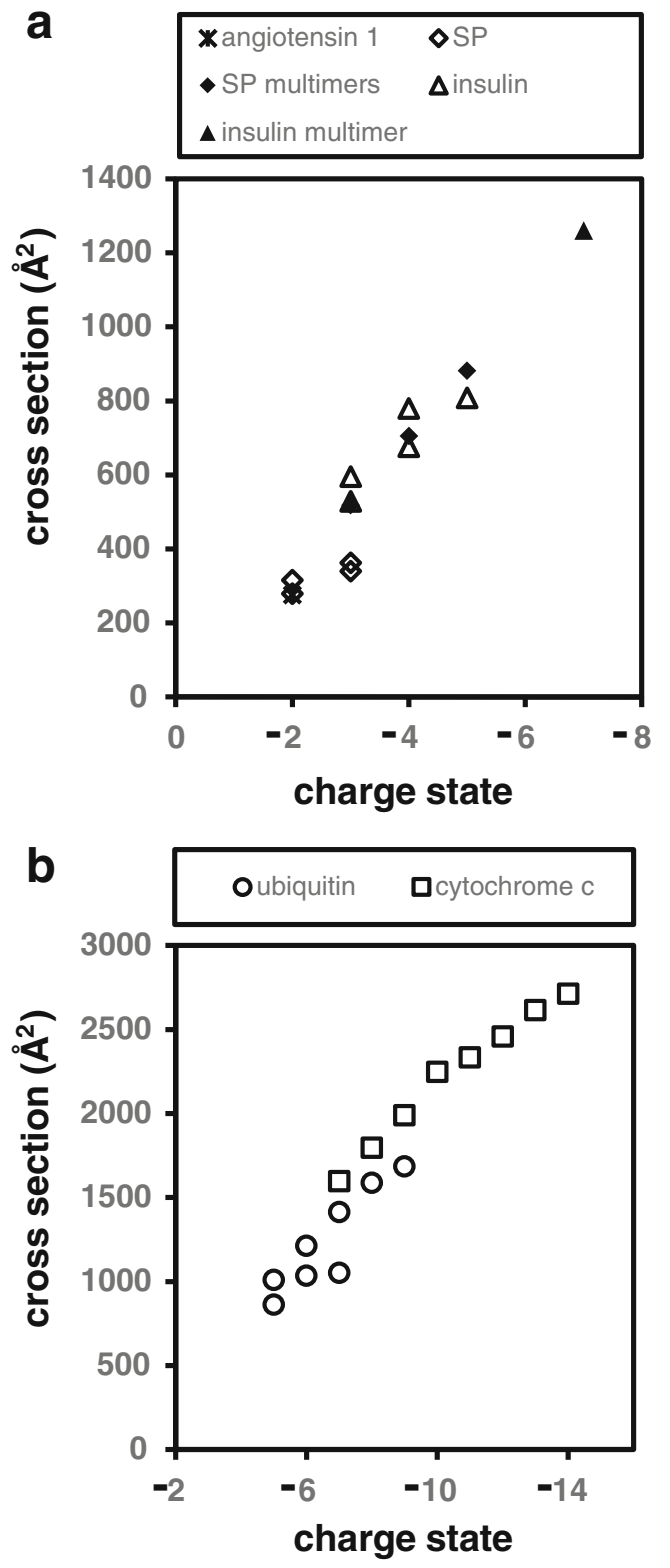

Figure 3. Collision cross-sections for peptide (a) and protein (b) ion conformers. The identities of the molecular ions are shown in the legend. The multimeric ions for SP are the [2M $3 \mathrm{H}]^{3-},[3 \mathrm{M}-4 \mathrm{H}]^{4-}$, and $[4 \mathrm{M}-5 \mathrm{H}]^{5-}$ ions. The multimeric insulin ion is the $[2 \mathrm{M}-7 \mathrm{H}]^{7-}$ species. The error associated with the cross-section measurement $(\mathrm{N}=3)$ is shown in Table 1

be determined and, therefore, both rate constants are reported in Table 1. Comparatively, these rate constants are similar to those reported previously for positively-charged protein ions exposed to $\mathrm{D}_{2} \mathrm{O}$ in a drift tube [26,27]. This determination is of interest, indicating that a similar charge-mediated exchange process (see below) could account for the observed HDX.

\section{Peptide and Protein Ion HDX Levels}

Figure 5a shows the maximum HDX levels for the dominant ion conformations (Table 1) of the smaller molecules (i.e., angiotensin 1, SP, and bovine insulin). The data indicate that, within molecular analyses, the smaller peptide ions of different charge exhibit similar HDX levels. That is, the HDX level of the SP and insulin ions does not increase with charge state. Interestingly, insulin HDX levels are comparable to those of SP despite having an overall higher charge state distribution and $\sim 4$-fold more exchangeable sites.

The maximum HDX levels of the dominant ion conformers (Table 1) from the globular proteins ubiquitin and cytochrome $c$ are shown in Figure 5b. For ubiquitin, the HDX levels for the $[\mathrm{M}-5 \mathrm{H}]^{5-}$ and $[\mathrm{M}-6 \mathrm{H}]^{6-}$ ions increase only slightly. Notably, the two ions have similar collision cross-sections (1010 and $1035 \AA^{2}$, respectively). The HDX level of the dominant [M $7 \mathrm{H}]^{7-}$ ions increases by nearly $\sim 40 \%$ relative to that of the $[\mathrm{M}-$ $6 \mathrm{H}]^{-6}$ ions. Similarly, the collision cross-section for these ions is observed to be $\sim 37 \%$ larger than that of the more compact, dominant $[\mathrm{M}-6 \mathrm{H}]^{6-}$ ions representing the largest conformational change between any ions observed in the charge state distribution for ubiquitin. An increase in HDX level $(\sim 20 \%)$ is also observed for the $[\mathrm{M}-8 \mathrm{H}]^{8-}$ ions relative to that of the $[\mathrm{M}-$ $7 \mathrm{H}]^{7-}$ ions, whereas the change in collision cross-section is smaller $(\sim 12 \%)$. The HDX levels of the $[\mathrm{M}-8 \mathrm{H}]^{8-}$ and $[\mathrm{M}-$ $9 \mathrm{H}]^{9-}$ ions are similar and the latter ions exhibit only a slightly larger collision cross-section $(\sim 6 \%)$. In general, the collision cross-section data show a transition for dominant dataset features going from compact conformations for the $[\mathrm{M}-6 \mathrm{H}]^{6-}$ ions to more elongated conformations for the $[\mathrm{M}-8 \mathrm{H}]^{8-}$ ions. The HDX levels reflect this transition as well; the more elongated species are observed to have greater deuterium incorporation.

Cytochrome $c$ is the largest biomolecule examined in this study. Figure $5 b$ shows the HDX levels for the ion conformations of cytochrome $c$. Overall, higher charge states are associated with increased HDX levels across the distribution and deuterium exchange proceeds in a nearly linear relationship with respect to increasing charge state. For example, exchange levels increase in a uniform manner from the $[\mathrm{M}-8 \mathrm{H}]^{8-}$ ions to the $[\mathrm{M}-12 \mathrm{H}]^{12-}$ ions and correspond to an overall increase of $\sim 50 \%$ ( $\sim 57$ to $\sim 85)$. Collision cross-sections increase by a nearly identical $53 \%$ (1599 to $2459 \AA^{2}$ ) across this charge state range.

\section{Gas-Phase HDX Levels of Multimeric Ions}

Figure 4a shows the HDX levels for several multimeric ions. For data evaluation purposes, it is useful to consider the deuterium uptake per monomer (total uptake/number of monomer subunits). For $[2 \mathrm{M}-3 \mathrm{H}]^{3-}$ ions of SP and $[2 \mathrm{M}-7 \mathrm{H}]^{7-}$ ions of insulin, the uptake per monomer unit is similar to the uptake observed for the monomer ions. However, for SP, multimeric ions display an increased level of protection with the addition of another monomer subunit. Here, the dimer and trimer maximum HDX levels are $\sim 30$ and $\sim 36$, respectively. That is, although the number of exchangeable hydrogens increases by $50 \%$ from the dimer to the trimer, the observed HDX level only increases by $\sim 17 \%$. 
Table 1. Collision Cross-Sections, HDX Levels, and Rate Constants for All Major Dataset Features

\begin{tabular}{|c|c|c|c|c|c|c|c|}
\hline \multirow[t]{2}{*}{ Sample } & \multirow[t]{2}{*}{ Ion } & \multirow[t]{2}{*}{ Cross-section $^{\mathrm{a}}$} & \multirow[t]{2}{*}{ HDX level ${ }^{\mathrm{b}}$} & \multicolumn{2}{|c|}{ Rate constants ${ }^{c}$} & \multicolumn{2}{|c|}{ Correlation coefficient ${ }^{\mathrm{d}}$} \\
\hline & & & & Fast & Slow & Fast & Slow \\
\hline Angiotensin I & {$[\mathrm{M}-2 \mathrm{H}]^{2-}$} & $275 \pm 2$ & $7.2 \pm 0.3$ & $1.9 \times 10^{-13}$ & $6.1 \times 10^{-14}$ & 0.991 & 0.966 \\
\hline \multirow[t]{7}{*}{ SP } & {$[\mathrm{M}-2 \mathrm{H}]^{2-}$} & $279 \pm 2$ & $15.1 \pm 0.2$ & $4.2 \times 10^{-13}$ & $5.3 \times 10^{-14}$ & 0.989 & 0.983 \\
\hline & {$[\mathrm{M}-2 \mathrm{H}]^{2-}$} & $315 \pm 2$ & NA & NA & & NA & \\
\hline & {$[\mathrm{M}-3 \mathrm{H}]^{3-}$} & $340 \pm 2$ & NA & NA & & NA & \\
\hline & {$[\mathrm{M}-3 \mathrm{H}]^{3-}$} & $362 \pm 2$ & $16.0 \pm 0.3$ & $6.4 \times 10^{-13}$ & $4.9 \times 10^{-14}$ & 0.982 & 0.764 \\
\hline & {$[2 \mathrm{M}-3 \mathrm{H}]^{3-}$} & $518 \pm 2$ & $30.2 \pm 0.3$ & NA & & NA & \\
\hline & {$[3 \mathrm{M}-4 \mathrm{H}]_{5}^{4-}$} & $705 \pm 3$ & $36.0 \pm 0.4$ & NA & & NA & \\
\hline & {$[4 \mathrm{M}-5 \mathrm{H}]^{5-}$} & $881 \pm 4$ & NA & NA & & NA & \\
\hline \multirow{6}{*}{ Insulin } & {$[\mathrm{M}-3 \mathrm{H}]^{3-}$} & $528 \pm 2$ & $14.8 \pm 0.3$ & $8.3 \times 10^{-14}$ & $1.9 \times 10^{-14}$ & 0.956 & 0.993 \\
\hline & {$[\mathrm{M}-3 \mathrm{H}]^{3-}$} & $595 \pm 2$ & NA & NA & & NA & \\
\hline & {$[\mathrm{M}-4 \mathrm{H}]^{4-}$} & $676 \pm 3$ & NA & NA & & NA & \\
\hline & {$[\mathrm{M}-4 \mathrm{H}]^{4-}$} & $779 \pm 3$ & $14.2 \pm 0.4$ & $1.0 \times 10^{-13}$ & $1.8 \times 10^{-14}$ & 0.952 & 0.973 \\
\hline & {$[\mathrm{M}-5 \mathrm{H}]^{5-}$} & $808 \pm 4$ & $14.1 \pm 0.5$ & $1.3 \times 10^{-13}$ & $3.2 \times 10^{-14}$ & 0.971 & 0.988 \\
\hline & {$[2 \mathrm{M}-7 \mathrm{H}]^{7-}$} & $1260 \pm 5$ & $26.8 \pm 0.7$ & NA & & NA & \\
\hline \multirow[t]{8}{*}{ Ubiquitin } & {$[\mathrm{M}-5 \mathrm{H}]^{5-}$} & $862 \pm 4$ & NA & NA & & NA & \\
\hline & {$[\mathrm{M}-5 \mathrm{H}]^{5-}$} & $1010 \pm 4$ & $27.8 \pm 0.5$ & $1.3 \times 10^{-13}$ & $6.5 \times 10^{-14}$ & 0.998 & 0.964 \\
\hline & {$[\mathrm{M}-6 \mathrm{H}]^{6-}$} & $1035 \pm 4$ & $28.3 \pm 0.6$ & $1.4 \times 10^{-13}$ & $5.4 \times 10^{-14}$ & 0.994 & 0.991 \\
\hline & {$[\mathrm{M}-\mathrm{H}]^{6-}$} & $1212 \pm 4$ & NA & NA & & NA & \\
\hline & {$[\mathrm{M}-7 \mathrm{H}]^{7-}$} & $1052 \pm 5$ & NA & NA & & NA & \\
\hline & {$[\mathrm{M}-7 \mathrm{H}]^{7-}$} & $1414 \pm 5$ & $39.4 \pm 0.7$ & $1.3 \times 10^{-13}$ & $5.9 \times 10^{-4}$ & 0.993 & 0.986 \\
\hline & {$[\mathrm{M}-8 \mathrm{H}]^{8-}$} & $1587 \pm 6$ & $47.7 \pm 0.8$ & $1.1 \times 10^{-13}$ & $3.9 \times 10^{-14}$ & 0.992 & 0.992 \\
\hline & {$[\mathrm{M}-9 \mathrm{H}]^{9-}$} & $1686 \pm 7$ & $46.4 \pm 0.9$ & $1.2 \times 10^{-13}$ & $3.6 \times 10^{-14}$ & 0.994 & 0.955 \\
\hline \multirow[t]{8}{*}{ Cytochrome $c$} & {$[\mathrm{M}-7 \mathrm{H}]^{7-}$} & $1598 \pm 5$ & $56.8 \pm 0.7$ & $2.1 \times 10^{-13}$ & $4.2 \times 10^{-14}$ & 0.981 & 0.947 \\
\hline & {$[\mathrm{M}-8 \mathrm{H}]^{8-}$} & $1797 \pm 6$ & $62.8 \pm 0.8$ & $1.9 \times 10^{-13}$ & $6.2 \times 10^{-14}$ & 0.977 & 0.969 \\
\hline & {$[\mathrm{M}-9 \mathrm{H}]^{9-}$} & $1990 \pm 7$ & $67.1 \pm 0.9$ & $2.0 \times 10^{-13}$ & $2.9 \times 10^{-14}$ & 0.996 & 0.998 \\
\hline & {$[\mathrm{M}-10 \mathrm{H}]^{10-}$} & $2247 \pm 7$ & $72 \pm 1$ & $2.1 \times 10^{-13}$ & $5.2 \times 10^{-14}$ & 0.998 & 0.968 \\
\hline & {$[\mathrm{M}-11 \mathrm{H}]^{11-}$} & $2334 \pm 8$ & $80 \pm 1$ & $3.2 \times 10^{-13}$ & $3.3 \times 10^{-14}$ & 0.970 & 0.969 \\
\hline & {$[\mathrm{M}-12 \mathrm{H}]^{12-}$} & $2458 \pm 9$ & $84 \pm 1$ & $3.9 \times 10^{-13}$ & $5.0 \times 10^{-14}$ & 0.999 & 0.820 \\
\hline & {$[\mathrm{M}-13 \mathrm{H}]^{13-}$} & $2615 \pm 10$ & NA & NA & & NA & \\
\hline & {$[\mathrm{M}-14 \mathrm{H}]^{14-}$} & $2713 \pm 10$ & NA & NA & & NA & \\
\hline
\end{tabular}

${ }^{\text {a }}$ Collision cross-sections reported as $\AA^{2}$

${ }^{\mathrm{b}} \mathrm{HDX}$ levels reported as average \pm standard deviation for triplicate measurements

${ }^{c}$ Rate constants reported as $\mathrm{cm}^{3} \cdot \mathrm{s}^{-1} \cdot \mathrm{cm}^{-1}$

${ }^{\mathrm{d}}$ Correlation coefficient for a linear fit to the rate constant data. See Figure 4 and text for details

\section{HDX Kinetics of Deprotonated Peptides} and Proteins

Table 1 lists fast- and slow-exchanging rate constants for the various ion conformers. As mentioned above, for many ions, two rate constants have been determined. On average, the larger rate constants are approximately six times larger than the smaller rate constants ranging from a factor of 13.1 to 2 for the $[\mathrm{M}-3 \mathrm{H}]^{3-} \mathrm{SP}$ ions and the $[\mathrm{M}-5 \mathrm{H}]^{5-}$ ubiquitin ions, respectively. Of the larger rate constants, the fastest $\left(\mathrm{k}=6.4 \times 10^{-13} \mathrm{~cm}^{3} \cdot \mathrm{s}^{-1} \cdot \mathrm{molecule}^{-1}\right)$ and slowest
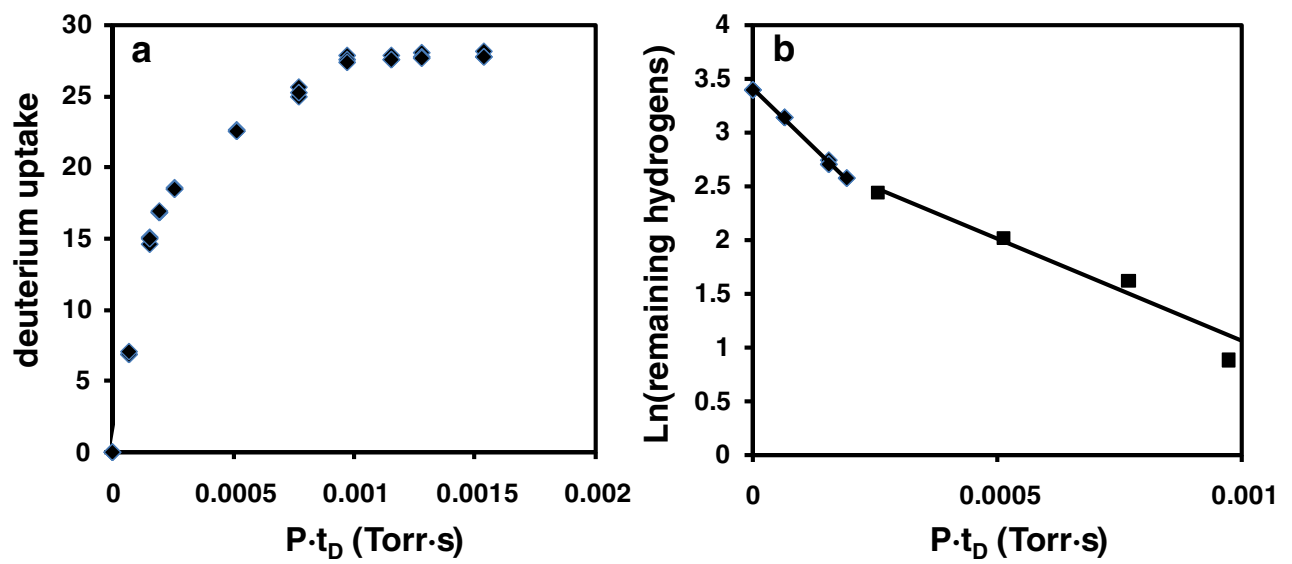

Figure 4. (a) Plot of deuterium uptake as a function of the partial pressure of $\mathrm{D}_{2} \mathrm{O}$ multiplied by $t_{D}$. This data was recorded for [M $5 \mathrm{H}]^{5-}$ ubiquitin ions (larger conformer). (b) Plot of the natural log of the number of remaining exchangeable hydrogens as a function of the product of $\mathrm{D}_{2} \mathrm{O}$ partial pressure and $t_{D}$. Linear fits of fast- and slow-exchanging hydrogens are shown 

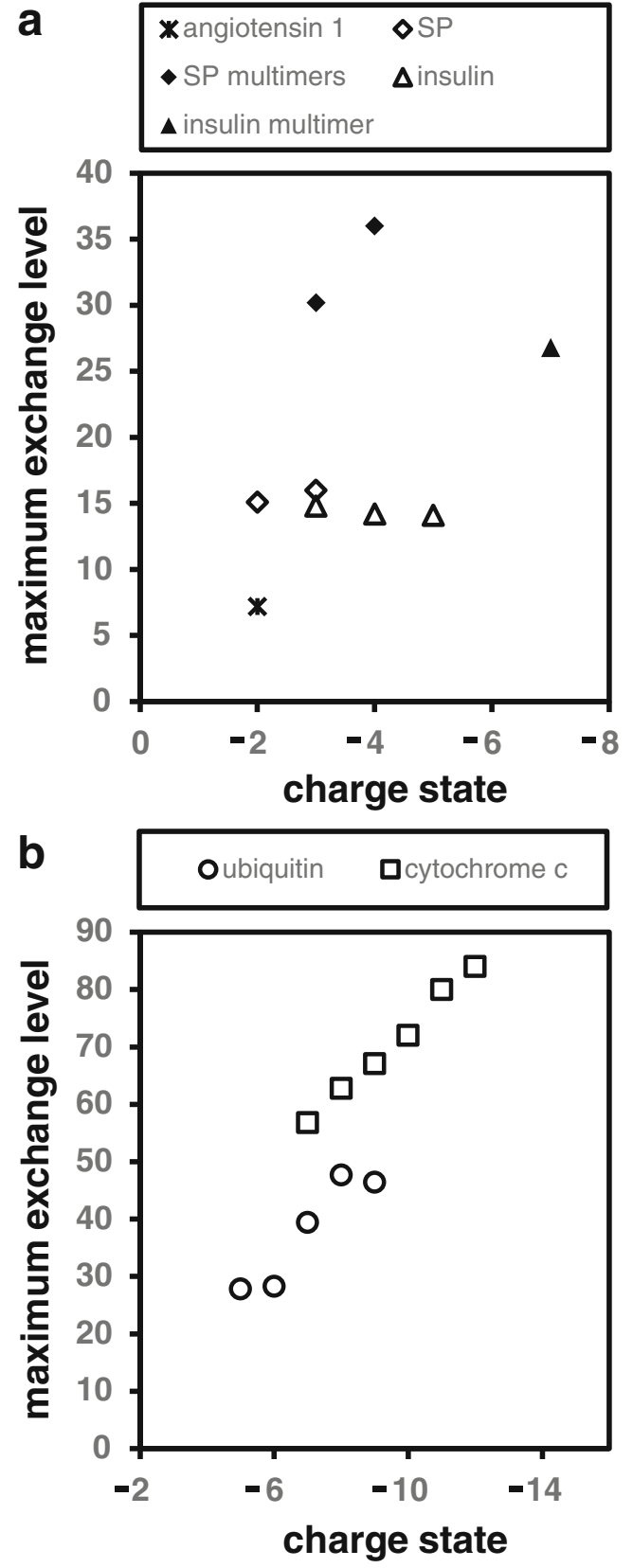

Figure 5. Plots of the maximum HDX levels for the dominant conformers of the peptide (a) and protein (b) ions. The identities of the molecular ions are shown in the legend. The multimeric ions for SP are the $[2 \mathrm{M}-3 \mathrm{H}]^{3-}$ and $[3 \mathrm{M}-4 \mathrm{H}]^{4-}$ ions. The multimeric insulin ion is the $[2 \mathrm{M}-7 \mathrm{H}]^{7-}$ species. The error associated with the HDX measurement $(\mathrm{N}=3)$ is shown in Table 1

$\left(\mathrm{k}=8.3 \times 10^{-14} \mathrm{~cm}^{3} \cdot \mathrm{s}^{-1} \cdot \mathrm{molecule}^{-1}\right)$ exchanging hydrogens are observed for $[\mathrm{M}-3 \mathrm{H}]^{3-}$ ions from SP and bovine insulin, respectively. For the smaller rate constants, the fastest $\left(\mathrm{k}=6.5 \times 10^{-14} \mathrm{~cm}^{3} \cdot \mathrm{s}^{-1} \cdot\right.$ molecule $\left.^{-1}\right)$ and slowest $\left(\mathrm{k}=1.8 \times 10^{-14} \mathrm{~cm}^{3} \cdot \mathrm{s}^{-1} \cdot \mathrm{molecule}^{-1}\right)$ exchanging hydrogens are observed for $[\mathrm{M}-5 \mathrm{H}]^{5-}$ ubiquitin and $[\mathrm{M}-4 \mathrm{H}]^{4-}$ insulin ions, respectively.
Unlike maximum HDX levels, the larger rate constants for the smaller molecules (SP and insulin) are observed to increase slightly with charge state. For the larger molecules, this trend is not observed. The average values for the larger rate constants are $1.9 \times 10^{-13}, 5.3$ $\pm 2.2 \times 10^{-13}, 1.0 \pm 0.2 \times 10^{-13}, 1.2 \pm 0.1 \times 10^{-13}$, and 2.5 $\pm 0.8 \times 10^{-13} \mathrm{~cm}^{3} \cdot \mathrm{s}^{-1} \cdot$ molecule $^{-1}$ for the angiotensin $1, \mathrm{SP}$, insulin, ubiquitin and cytochrome $c$ ions, respectively. The average values for the smaller rate constants are $6.1 \times 10^{-14}$, $5.1 \pm 0.4 \times 10^{-14}, 2.3 \pm 0.8 \times 10^{-14}, 5.0 \pm 1.0 \times 10^{-14}, 4.5 \pm 1.6 \times 10$ ${ }^{-14} \mathrm{~cm}^{3} \cdot \mathrm{s}^{-1} \cdot$ molecule $^{-1}$ for the same molecules. Here, the errors represent one standard deviation about the mean except in the case of SP where the difference was utilized.

\section{Structural Implications of the HDX Results}

To discuss the IMS and HDX information with regard to ion structure, it is useful to consider the process of HDX for negative ions. Although a mechanism for HDX with peptide anions and $\mathrm{D}_{2} \mathrm{O}$ has not been presented in the literature, studies with other anion systems suggest the possibility of a relay mechanism [37, 39, 43]. For peptides, the exchange would occur via a long-lived reaction intermediate involving interaction of the $\mathrm{D}_{2} \mathrm{O}$ molecule at the deprotonated site as well as a less acidic site (e.g., the neutral carboxylic acid moiety of a neighboring acidic amino acid residue). Exchange would proceed with deuterium transfer to the charge site and abstraction of the proton from the less acidic site. In this regard, the accessibility of a given hetero-atom site could be described with regard to its accessibility or proximity to a charge site as described previously for positively-charged ions [23, 27]. An additional factor would be the conformational flexibility of the specific ions [27, 36, 92]; that is, molecular motions that can position charge sites within an accessible range of exchange sites should also be considered. Finally, accessibility of exchange sites to collision events is also required. Further discussion of structural interpretation of the data is presented with respect to such processes.

The maximum exchange level of the $[\mathrm{M}-2 \mathrm{H}]^{2-}$ angiotensin 1 ions constitutes $\sim 40 \%$ of all exchangeable hydrogens, whereas the maximum exchange level for the $[\mathrm{M}-2 \mathrm{H}]^{2-}$ SP ions of similar cross-section accounts for $\sim 60 \%$ of all exchangeable hydrogens. A difference between the two peptide ions is the location of charge sites. The amino acid composition of angiotensin 1 (DRVYIHPFHL) requires that the charge sites reside on the $\mathrm{N}$-terminal aspartic acid residue and the $\mathrm{C}$-terminus. For the SP (KKDDDDDIIKIIK) ions, although one charge may reside at the $\mathrm{C}$-terminus, the second charge would be located on an interior aspartic acid residue. Additionally, the relatively compact nature of the larger (amino acid length) SP ions suggests a greater density of exchange sites. These two factors (more exchange sites flanking the charge site and their higher density) could account for higher exchange levels of the SP ions. This exchange-site and charge-site density argument has been presented recently in site-specific deuterium uptake studies of positively-charged SP ions [36]. 
The similarity in maximum HDX levels of the $[\mathrm{M}-2 \mathrm{H}]^{2-}$ and $[\mathrm{M}-3 \mathrm{H}]^{3-}$ SP ions is likely to result from a similar degree of accessibility to the exchange sites by the charge sites. For example, for this peptide, the $[\mathrm{M}-3 \mathrm{H}]^{3-}$ ions are $~ 30 \%$ larger than the $[\mathrm{M}-2 \mathrm{H}]^{2-}$ ions. The compact nature of the latter ions would position the two charge sites within proximity of a greater number of exchange sites while ion elongation of the former ions requires an additional charge site to access nearly the same number of exchange sites. It is noteworthy that the SP peptide ions exhibit maximum HDX levels for which a greater proportion of exchangeable hydrogens are observed to exchange. For example, SP is the only molecule for which nearly $60 \%$ of hetero-atom hydrogens are observed to exchange for both ion conformers. The small size of the SP ions can explain the observation of a higher proportion of deuterium uptake. Essentially all exchange sites would be accessible to $\mathrm{D}_{2} \mathrm{O}$ even for the compact $[\mathrm{M}-2 \mathrm{H}]^{2-}$ ions.

The insulin ions exhibit the smallest HDX levels and the slowest exchange rates. The observation of decreased HDX levels for ions formed from proteins with disulfide bonds has been reported previously for positively charged ions [92]. As before, it is proposed that conformational rigidity of insulin ions results in the decreased exchange. That is, limitations in molecular motion result in decreased access to exchange sites by charge sites. For ubiquitin ions, conformational rigidity and accessibility to $\mathrm{D}_{2} \mathrm{O}$ can explain the observed HDX levels. For example, the compact nature of the $[\mathrm{M}-5 \mathrm{H}]^{5-}$ and $[\mathrm{M}-6 \mathrm{H}]^{6-}$ ions may prevent access of specific exchange sites to $\mathrm{D}_{2} \mathrm{O}$; protection by compact structures for positively charged cytochrome $c$ ions has been presented previously [26]. It is noted that the compact nature can also provide conformational rigidity as demonstrated in previous temperature-dependent molecular modeling studies [27]. For the more elongated, higher charge states of ubiquitin, the increased accessibility of exchange sites to $\mathrm{D}_{2} \mathrm{O}$ and increased conformational flexibility could account for the increased HDX levels. Finally, for the multiply charged cytochrome $c$ ions, the relatively elongated nature of the ions would also expose more exchange sites to the $\mathrm{D}_{2} \mathrm{O}$ and the charge sites. The exposure to charge sites would increase with increasing charge and result in the observed higher HDX levels of these ions.

The increasing exchange levels with ion charge is not observed for the $[\mathrm{M}-2 \mathrm{H}]^{2-}$ and $[\mathrm{M}-3 \mathrm{H}]^{3-}$ SP ions, which display similar exchange levels. It is noted that for the peptide ions, the charge densities (charge per cross-section) are similar and nearly 2 -fold higher than the cytochrome $c$ ions. Interestingly, the increased charge density may impose a degree of conformational rigidity (as proposed previously [36]), which would offset hydrogen site accessibility with increased charge for the small peptide ions.

\section{Exchange Efficiency and the Protein Fold}

The discussion above of the maximum HDX levels for dominant ubiquitin ion conformers demonstrates that HDX levels correlate to a conformational transformation occurring for the
$[\mathrm{M}-6 \mathrm{H}]^{6-}$ and $[\mathrm{M}-7 \mathrm{H}]^{7-}$ ions. However, these maximum HDX levels do not reveal the degree to which increased exchange can be ascribed to protein fold versus an increase in the number of charge sites. To investigate this issue, HDX levels were recorded for compact and more elongated species for ions of both charge states at reduced $\mathrm{D}_{2} \mathrm{O}$ partial pressures $(0.04$ Torr). The lower pressure was utilized to ensure sufficient signal of lower abundance conformers, while at the same time determining differences in the levels of rapidly exchanging hydrogens (see Figure 4). Figure 6a shows an expanded region of a $t_{D}, m / z$ distribution for ubiquitin ions centered on compact
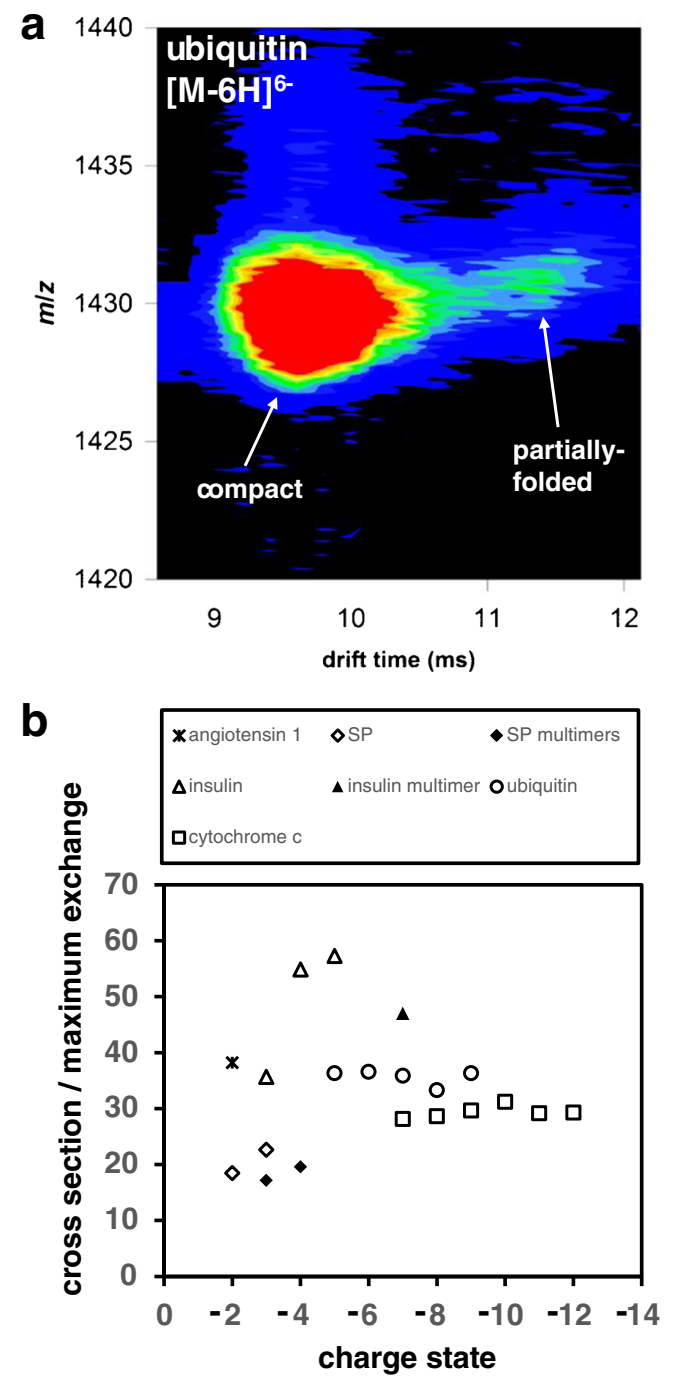

Figure 6. (a) Expanded region of a $t_{D}, \mathrm{~m} / \mathrm{z}$ contour plot showing $[\mathrm{M}-6 \mathrm{H}]^{6-}$ ubiquitin ions. For this experiment, a He:D2O (2.50:0.04 Torr) buffer gas mixture was utilized in the drift tube. The compact and partially-folded conformations are labeled. The maximum intensity cutoff is six ion counts. (b) Plot of exchange efficiency (cross-section/maximum HDX level) as a function of charge state. The identities of the molecular ions are shown in the legend. The multimeric ions for SP are the [2M $3 \mathrm{H}]^{3-}$ and $[3 \mathrm{M}-4 \mathrm{H}]^{4-}$ ions. The multimeric insulin ion is the $[2 \mathrm{M}-7 \mathrm{H}]^{7-}$ species 
and more elongated states of $[\mathrm{M}-6 \mathrm{H}]^{6-}$ conformers. On average, for the rapidly exchanging hydrogens, the more elongated conformer exhibits a $\mathrm{m} / \mathrm{z}$ value that is $\sim 1$ unit higher than the more compact conformer indicating an increased level of exchange corresponding to $\sim 6$ deuteriums. This same increase is also observed for more elongated $[\mathrm{M}-7 \mathrm{H}]^{7-}$ ions compared with more compact species of the same charge. These observations suggest that roughly half of the increase in deuterium incorporation $\left(\sim 11\right.$ deuteriums) from the compact $[\mathrm{M}-6 \mathrm{H}]^{6-}$ ions to the more elongated $[\mathrm{M}-7 \mathrm{H}]^{7-}$ ions may be attributed to the protein fold whereas the remaining difference may be accounted for by the addition of a charge site.

A more subtle contribution of exchange site protection provided by protein fold (i.e., locating exchange sites in interior regions) may be explained upon examining what is here termed as exchange efficiency for the different ion conformers. Exchange efficiency can be represented as the ratio of ion collision cross-ection to maximum HDX level. Figure 6b shows these ratios for all ions for which maximum HDX levels could be determined. A comparison of values determined for ubiquitin ions with those of cytochrome $\mathrm{c}$ ions suggests that the former ions exhibit slightly increased protection due to protein fold. That is, lower exchange efficiency is observed for the ubiquitin ions even though, on average, they exhibit a higher $(\sim 14 \%)$ charge site density. This lower exchange efficiency could result from slightly less accessibility to buried exchange sites.

For peptide ions, Figure 6 shows that the SP ion conformers experience the most efficient exchange. As mentioned above, this could result from near complete accessibility by $\mathrm{D}_{2} \mathrm{O}$; the relatively limited protection would then be primarily dictated by access to charge sites. Also, as described above, the relatively low exchange efficiencies of angiotensin 1 and insulin ion conformers are suggested to result from conformational rigidity. For the angiotensin peptide, this results from the location of charge sites at the peptide termini such that some interior exchange sites may become inaccessible to charge sites. For the insulin ions, conformational rigidity imposed by the disulfide bonds would account for the lowest exchange efficiency as previously observed for positively-charged protein ions with disulfide bonds [92].

The multimeric SP ions $\left([2 \mathrm{M}-3 \mathrm{H}]^{3-}\right.$ and $\left.[3 \mathrm{M}-4 \mathrm{H}]^{4-}\right)$ exhibit the highest exchange efficiencies as depicted in Figure 6. Additionally, the exchange efficiencies are very similar. That is, nearly the same number of deuteriums is incorporated per cross-sectional area for both ions. However, as mentioned above, the $[3 \mathrm{M}-4 \mathrm{H}]^{4-}$ ions exchange a relatively smaller proportion of total hydrogens compared to the $[2 \mathrm{M}-3 \mathrm{H}]^{3-}$ ions. Additionally, because the charge density is similar for both ion conformers, it may be assumed that charge location plays a major role in protection for the trimer ions. For example, one monomer unit of the trimer could contain two charge sites where one or both of these sites are not accessible to exchange sites on one of the other subunits. Alternatively, the addition of another monomer unit could decrease conformational flexibility, resulting in the lower maximum HDX value.
The data for the $[2 \mathrm{M}-7 \mathrm{H}]^{7-}$ insulin ions yield an exchange efficiency that is similar to the monomeric insulin ions, suggesting that the conformational rigidity afforded by the disulfide bonds also affects the maximum HDX level that can be achieved by these ions.

Having described the HDX levels and rates with regard to protein fold and conformational flexibility, it is instructive to present an alternative explanation for the experimental results. Over the last two decades, seminal research has indicated a propensity for gas-phase peptide and protein ions as well as ion complexes to form salt bridges in the gas phase [14, 93, 94]. Arguably, such salt-bridge structures impose a degree of conformational inflexibility [14], which could prevent exchange even at sites more proximal to charge sites. That said, here the argument of the necessity of charge site and exchange site proximity has been advanced based on the explanations provided for the observed maximum HDX levels and exchange efficiencies. The uniform increase in exchange levels for extended conformations of cytochrome $c$ with additional charge as well as the differences in efficiencies between ubiquitin and cytochrome $c$ suggest deuterium uptake near charge sites. Additionally, the comparison of exchange levels for the peptides angiotensin 1 and SP suggest that although both peptides are relatively small, providing access to $\mathrm{D}_{2} \mathrm{O}$ molecules, for $\mathrm{SP}$ ions, the positioning of charges on interior residues closer to exchange sites yields an increased proportion of exchanged hydrogens. This occurs even though acidic and basic residues are observed in adjacent positions of the peptide; that is, even with the increased propensity of forming ion conformers with salt-bridges (attributable to the large number of neighboring basic residues [95]), increased exchange and larger exchange rates are observed. That said, a large impact of salt-bridges on the HDX process as well as other factors that may be associated with the fast- and slow-exchanging sites cannot be ruled out. Indeed, the work presented here lays the foundation for testing different exchange models as initiated in recent peptide ion conformer studies [36].

\section{Experimental Limitations and Future Directions}

The combination of IMS with HDX-MS demonstrates a powerful approach for characterizing the ion structures of negatively-charged biomolecular ions. The use of nonergodic ion fragmentation techniques with MS analysis has proven to be useful in the localization of HDX sites [31, 32]. More recently, IMS-HDX experiments have been coupled with ETD-MS to determine deuterium uptake sites for specific conformations of positively charged ions for the SP peptide described here [36]. The addition of a suitable, nonergodic ion fragmentation technique with IMS-HDX characterization of specific peptide and protein anions would allow similar determinations for the specific peptide and protein ions presented here. The development of new ion fragmentation methods offers promise for these experiments [46, 48, 49, 96, 97].

Previously, molecular dynamics simulations have been used with IMS-HDX-MS results to help explain the HDX levels 
observed for positively charged peptide and protein ions [23, 27]. The recent experiments combining IMS-HDX and ETDMS with molecular dynamics simulations suggest a need for a refinement of the previous models for deuterium incorporation (i.e., those considering only the distance between exchange sites and charge sites) [36]. The observation that many of exchangeable hydrogens on charge sites do not undergo exchange necessitated the consideration of other models to be explored by molecular dynamics simulations. Indeed a model that incorporated distances to the charge site as well as to less basic sites using computer-generated peptide ion structures provides a better fit to experimentally determined deuterium uptake by individual amino acid residues [36]. Extending the experimental capabilities to allow determination of deuterium uptake at individual residues and the development of models from molecular dynamics simulations to explain these uptake levels are under investigation.

\section{Conclusions}

The HDX characteristics of negatively charged ion conformers for peptides and proteins have been studied with IMS-MS techniques. The observation of HDX levels corresponding to large percentages of exchangeable hydrogens for the SP peptide ions suggests greater access of charge sites to exchange sites as well as to the $\mathrm{D}_{2} \mathrm{O}$ molecules. The estimation of the largest exchange rates for these ions is consistent with this explanation. Comparatively, for the angiotensin 1 peptide ions, the decreased HDX level suggests decreased access to exchange sites by charge sites because of the most likely location of the charge sites on the peptide termini. Electrosprayed insulin ions exhibit the lowest HDX levels, which can be attributed to decreased conformational flexibility resulting from the restraining disulfide bonds. This is further supported by the observation of the low exchange rates for these ions. HDX levels of larger proteins are observed to increase with charge state and ion size consistent with a charge-mediated exchange process. Of note, the HDX levels for ubiquitin ions scale with a conformational transition from more compact species to more elongated species. Based on comparisons to exchange protection for compact and elongated ion conformers, it is proposed that the exchange level transition results in part from protein fold exchange site protection and decreased access to charge sites for ubiquitin ions of lower charge. Finally, exchange efficiency comparisons suggest that ubiquitin ion conformers provide increased protection of interior sites relative to cytochrome $c$ ions. Together, the results demonstrate the utility of the combined IMS and HDX conformational probes for obtaining structural information. Moreover, these studies lay the groundwork for powerful new approaches where additional tools, including the incorporation of novel ion fragmentation techniques and the use of molecular dynamics simulations, can be used to refine the structural information afforded by IMS-HDX measurements.

\section{Acknowledgments}

The authors are grateful for financial support from the Eberly College of Arts and Sciences at West Virginia University for providing laboratory research startup funds, as well as the Brodie Discovery and Innovation Award. Additionally, partial support has been provided by the 2012-2013 Starter Grant Award from the Society of Analytical Chemists of Pittsburgh (SACP), as well as the 2012-2013 Ralph E. Powe Junior Faculty Advancement Award from Oak Ridge Associated Universities (ORAU).

\section{References}

1. Fenn, J.B., Mann, M., Meng, C.K., Wong, S.F., Whitehouse, C.M.: Electrospray ionization for mass-spectrometry of large biomolecules. Science 246(4926), 64-71 (1989)

2. Hillenkamp, F., Karas, M., Beavis, R.C., Chait, B.T.: Matrix-assisted laser desorption ionization mass-spectrometry of biopolymers. Anal. Chem. 63 (24), A1193-A1202 (1991)

3. Tanaka, K., Waki, H., Ido, Y., Akita, S., Yoshida, Y., Yoshida, T., Matsuo, T.: Protein and polymer analyses up to $m / z 100,000$ by laser ionization time-of-flight mass spectrometry. Rapid Commun. Mass Spectrom. 2(8), 151-153 (1988)

4. Loo, J.A., Edmonds, C.G., Smith, R.D.: Primary sequence information from intact proteins by electrospray ionization tandem mass spectrometry. Science 248(4952), 201-204 (1990)

5. Cheng, X.H., Fenselau, C.: Hydrogen-deuterium exchange of massselected peptide ions with ND3 in a tandem sector mass-spectrometer. Int. J. Mass Spectrom. Ion Process. 122, 109-119 (1992)

6. Suckau, D., Shi, Y., Beu, S.C., Senko, M.W., Quinn, J.P., Wampler, F.M., McLafferty, F.W.: Coexisting stable conformations of gaseous protein ions. Proc. Natl. Acad. Sci. U. S. A. 90(3), 790-793 (1993)

7. Covey, T., Douglas, D.J.: Collision cross-sections for protein ions. J. Am. Soc. Mass Spectrom. 4(8), 616-623 (1993)

8. Campbell, S., Rodgers, M.T., Marzluff, E.M., Beauchamp, J.L.: Deuterium exchange reactions as a probe of biomolecule structure. Fundamental studies of cas phase H/D exchange reactions of protonated glycine oligomers with D2O, CD3OD, CD3CO2D, and ND3. J. Am. Chem. Soc. 117 (51), 12840-12854 (1995)

9. Clemmer, D.E., Hudgins, R.R., Jarrold, M.F.: Naked protein conformations: cytochrome $c$ in the gas phase. J. Am. Chem. Soc. 117(40), 1014110142 (1995)

10. Meot-Ner, M., Dongre, A.R., Somogyi, A., Wysocki, V.H.: Thermal decomposition kinetics of protonated peptides and peptide dimers, and comparison with surface-induced dissociation. Rapid Commun. Mass Spectrom. 9(9), 829-836 (1995)

11. Kaltashov, I.A., Fabris, D., Fenselau, C.C.: Assessment of gas-phase basicities of protonated peptides by the kinetic method. J. Phys. Chem. 99 (24), 10046-10051 (1995)

12. Williams, E.R.: Proton transfer reactivity of large multiply charged ions. J. Mass Spectrom. 31(8), 831-842 (1996)

13. Dongre, A.R., Jones, J.L., Somogyi, A., Wysocki, V.H.: Influence of peptide composition, gas-phase basicity, and chemical modification on fragmentation efficiency: evidence for the mobile proton model. J. Am. Chem. Soc. 118(35), 8365-8374 (1996)

14. Schnier, P.D., Price, W.D., Jockusch, R.A., Williams, E.R.: Blackbody infrared radiative dissociation of bradykinin and its analogues: energetics, dynamics, and evidence for salt-bridge structures in the gas phase. J. Am. Chem. Soc. 118(30), 7178-7189 (1996)

15. Green, M.K., Lebrilla, C.B.: Ion-molecule reactions as probes of gas-phase structures of peptides and proteins. Mass Spectrom. Rev. 16(2), 53-71 (1997)

16. Rodriguez-Cruz, S.E., Klassen, J.S., Williams, E.R.: Hydration of gasphase gramicidin $\mathrm{S}(\mathrm{M}+2 \mathrm{H}) 2+$ ions formed by electrospray: the transition from solution to gas-phase structure. J. Am. Soc. Mass Spectrom. 8(5), 565-568 (1997)

17. Stephenson, J.L., McLuckey, S.A.: Gaseous protein cations are amphoteric. J. Am. Chem. Soc. 119(7), 1688-1696 (1997) 
18. Javahery, G., Thomson, B.: A segmented radiofrequency-only quadrupole collision cell for measurements of ion collision cross-section on a triple quadrupole mass spectrometer. J. Am. Soc. Mass Spectrom. 8(7), 697-702 (1997)

19. Dugourd, P., Hudgins, R.R., Clemmer, D.E., Jarrold, M.F.: High-resolution ion mobility measurements. Rev. Sci. Instrum. 68(2), 1122-1129 (1997)

20. Valentine, S.J., Counterman, A.E., Clemmer, D.E.: Conformer-dependent proton-transfer reactions of ubiquitin ions. J. Am. Soc. Mass Spectrom. 8 (9), 954-961 (1997)

21. Wood, T.D., Chorush, R.A., Wampler, F.M., Little, D.P., Oconnor, P.B., McLafferty, F.W.: Gas-phase folding and unfolding of cytochrome- $c$ cations. Proc. Natl. Acad. Sci. U. S. A. 92(7), 2451-2454 (1995)

22. Gard, E., Green, M.K., Bregar, J., Lebrilla, C.B.: Gas-phase hydrogen/ deuterium exchange as a molecular probe for the interaction of methanol and protonated peptides. J. Am. Soc. Mass Spectrom. 5(7), 623-631 (1994)

23. Wyttenbach, T., Bowers, M.T.: Gas phase conformations of biological molecules: the hydrogen/deuterium exchange mechanism. J. Am. Soc. Mass Spectrom. 10(1), 9-14 (1999)

24. Freitas, M.A., Hendrickson, C.L., Emmett, M.R., Marshall, A.G.: Gasphase bovine ubiquitin cation conformations resolved by gas-phase hydrogen/deuterium exchange rate and extent. Int. J. Mass Spectrom. 185, 565-575 (1999)

25. Wyttenbach, T., vonHelden, G., Bowers, M.T.: Gas-phase conformation of biological molecules: bradykinin. J. Am. Chem. Soc. 118(35), 8355-8364 (1996)

26. Valentine, S.J., Clemmer, D.E.: H/D exchange levels of shape-resolved cytochrome c conformers in the gas phase. J. Am. Chem. Soc. 119(15), 3558-3566 (1997)

27. Valentine, S.J., Clemmer, D.E.: Temperature-dependent H/D exchange of compact and elongated cytochrome $c$ ions in the gas phase. J. Am. Soc. Mass Spectrom. 13(5), 506-517 (2002)

28. Zubarev, R.A., Kelleher, N.L., McLafferty, F.W.: Electron capture dissociation of multiply charged protein cations. A nonergodic process. J. Am. Chem. Soc. 120(13), 3265-3266 (1998)

29. Syka, J.E.P., Coon, J.J., Schroeder, M.J., Shabanowitz, J., Hunt, D.F.: Peptide and protein sequence analysis by electron transfer dissociation mass spectrometry. Proc. Natl. Acad. Sci. U. S. A. 101(26), 9528-9533 (2004)

30. Rand, K.D., Pringle, S.D., Murphy, J.P., Fadgen, K.E., Brown, J., Engen, J.R.: Gas-phase hydrogen/deuterium exchange in a traveling wave ion guide for the examination of protein conformations. Anal. Chem. 81(24), 10019-10028 (2009)

31. Rand, K.D., Pringle, S.D., Morris, M., Brown, J.M.: Site-specific analysis of gas-phase hydrogen/deuterium exchange of peptides and proteins by electron transfer dissociation. Anal. Chem. 84(4), 1931-1940 (2012)

32. Rand, K.D., Pringle, S.D., Morris, M., Engen, J.R., Brown, J.M.: ETD in a traveling wave ion guide at tuned z-spray ion source conditions allows for site-specific hydrogen/deuterium exchange measurements. J. Am. Soc. Mass Spectrom. 22(10), 1784-1793 (2011)

33. Rand, K.D., Pringle, S.D., Murphy III, J.P., Fadgen, K.E., Brown, J., Engen, J.R.: Gas-phase hydrogen/deuterium exchange in a traveling wave ion guide for the examination of protein conformations. Anal. Chem. 81 (24), 10019-10028 (2009)

34. Morsa, D., Gabelica, V., De Pauw, E.: Effective temperature of ions in traveling wave ion mobility spectrometry. Anal. Chem. 83(14), 5775-5782 (2011)

35. Merenbloom, S.I., Flick, T.G., Williams, E.R.: How hot are your ions in TWAVE ion mobility spectrometry? J. Am. Soc. Mass Spectrom. 23(3), 553-562 (2012)

36. Khakinejad, M.M, H., Arndt, J.R., Donohoe, G.C., Valentine, S.J.: Combining ion mobility spectrometry with hydrogen-deuterium exchange and top-down MS for peptide ion structure analysis. J. Am. Soc. Mass Spectrom. 25(12), 2103-2115 (2014)

37. Chan, S., Enke, C.G.: Mechanistic study of hydrogen/deuterium exchange between $[\mathrm{M}-1]^{-}$ions of chlorinated benzenes and D2O or ND3. J. Am. Soc. Mass Spectrom. 5(4), 282-291 (1994)

38. Robinson, J.M., Greig, M.J., Griffey, R.H., Mohan, V., Laude, D.A.: Hydrogen/deuterium exchange of nucleotides in the gas phase. Anal. Chem. 70(17), 3566-3571 (1998)

39. Freitas, M.A., Shi, S.D.H., Hendrickson, C.L., Marshall, A.G.: Gas-phase RNA and DNA ions. 1. H/D exchange of the $\mathrm{M}-\mathrm{H}(-)$ anions of nucleoside 5'-monophosphates (GMP, dGMP, AMP, dAMP, CMP, dCMP, UMP, dTMP), ribose 5-monophosphate, and 2-deoxyribose 5monophosphate with D2O and D2S. J. Am. Chem. Soc. 120(39), 1018710193 (1998)
40. Chipuk, J.E., Brodbelt, J.S.: Gas-phase hydrogen/deuterium exchange of 5 '- and 3 '-mononucleotides in a quadrupole ion trap: exploring the role of conformation and system energy. J. Am. Soc. Mass Spectrom. 18(4), 724736 (2007)

41. Freitas, M.A., Marshall, A.G.: Gas phase RNA and DNA ions. 2. Conformational dependence of the gas-phase H/D exchange of nucleotide-5'monophosphates. J. Am. Soc. Mass Spectrom 12(7), 780-785 (2001)

42. Crestoni, M.E., Fornarini, S.: Gas-phase hydrogen/deuterium exchange of adenine nucleotides. J. Mass Spectrom. 38(8), 854-861 (2003)

43. Tian, Z., Lis, L., Kass, S.R.: Hydrogen-deuterium exchange and selective labeling of deprotonated amino acids and peptides in the gas phase. J. Am. Chem. Soc. 130(1), 8-9 (2008)

44. Bache, N., Rand, K.D., Roepstorff, P., Ploug, M., Jorgensen, T.J.: Hydrogen atom scrambling in selectively labeled anionic peptides upon collisional activation by MALDI tandem time-of-flight mass spectrometry. J. Am. Soc. Mass Spectrom. 19(12), 1719-1725 (2008)

45. Allen, S.J., Schwartz, A.M., Bush, M.F.: Effects of polarity on the structures and charge states of native-like proteins and protein complexes in the gas phase. Anal. Chem. 85(24), 12055-12061 (2013)

46. Yoo, H.J., Wang, N., Zhuang, S., Song, H., Hakansson, K.: Negative-ion electron capture dissociation: radical-driven fragmentation of chargeincreased gaseous peptide anions. J. Am. Chem. Soc. 133(42), 16790$16793(2011)$

47. Hersberger, K.E., Hakansson, K.: Characterization of O-sulfopeptides by negative ion mode tandem mass spectrometry: superior performance of negative ion electron capture dissociation. Anal. Chem. 84(15), 6370-6377 (2012)

48. Cook, S.L., Zimmermann, C.M., Singer, D., Fedorova, M., Hoffmann, R., Jackson, G.P.: Comparison of CID, ETD and metastable atom-activated dissociation (MAD) of doubly and triply charged phosphorylated tau peptides. J. Mass Spectrom. 47(6), 786-794 (2012)

49. Cook, S.L., Collin, O.L., Jackson, G.P.: Metastable atom-activated dissociation mass spectrometry: leucine/isoleucine differentiation and ring cleavage of proline residues. J. Mass Spectrom. 44(8), 1211-1223 (2009)

50. Zhou, M.W., Wysocki, V.H.: Surface induced dissociation: dissecting noncovalent protein complexes in the gas phase. Acc. Chem. Res. 47(4), $1010-1018$ (2014)

51. Zhou, M.W., Huang, C.S., Wysocki, V.H.: Surface-induced dissociation of ion mobility-separated noncovalent complexes in a quadrupole/time-offlight mass spectrometer. Anal. Chem. 84(14), 6016-6023 (2012)

52. Hoaglund, C.S., Valentine, S.J., Sporleder, C.R., Reilly, J.P., Clemmer, D.E.: Three-dimensional ion mobility TOFMS analysis of electrosprayed biomolecules. Anal. Chem. 70(11), 2236-2242 (1998)

53. Hoaglund, C.S., Valentine, S.J., Clemmer, D.E.: An ion trap interface for ESI-ion mobility experiments. Anal. Chem. 69(20), 4156-4161 (1997)

54. Valentine, S.J., Koeniger, S.L., Clemmer, D.E.: A split-field drift tube for separation and efficient fragmentation of biomolecular ions. Anal. Chem. 75(22), 6202-6208 (2003)

55. Merenbloom, S.I., Koeniger, S.L., Valentine, S.J., Plasencia, M.D., Clemmer, D.E.: IMS-IMS and IMS-IMS-IMS/MS for separating peptide and protein fragment ions. Anal. Chem. 78(8), 2802-2809 (2006)

56. Wittmer, D., Luckenbill, B.K., Hill, H.H., Chen, Y.H.: Electrosprayionization ion mobility spectrometry. Anal. Chem. 66(14), 2348-2355 (1994)

57. Hoadlund-Hyzer, C.S., Li, J.W., Clemmer, D.E.: Mobility labeling for parallel CID of ion mixtures. Anal. Chem. 72(13), 2737-2740 (2000)

58. Wu, C., Siems, W.F., Asbury, G.R., Hill, H.H.: Electrospray ionization high-resolution ion mobility spectrometry-mass spectrometry. Anal. Chem. 70(23), 4929-4938 (1998)

59. Gillig, K.J., Ruotolo, B., Stone, E.G., Russell, D.H., Fuhrer, K., Gonin, M., Schultz, A.J.: Coupling high-pressure MALDI with ion mobility/ orthogonal time-of flight mass spectrometry. Anal. Chem. 72(17), 3965$3971(2000)$

60. Ruotolo, B.T., Gillig, K.J., Stone, E.G., Russell, D.H.: Peak capacity of ion mobility mass spectrometry: separation of peptides in helium buffer gas. J. Chromatogr. B Anal. Technol. Biomed. Life Sci. 782(1/2), 385-392 (2002)

61. Clowers, B.H., Hill, H.H.: Mass analysis of mobility-selected ion populations using dual gate, ion mobility, quadrupole ion trap mass spectrometry. Anal. Chem. 77(18), 5877-5885 (2005)

62. Clowers, B.H., Siems, W.F., Hill, H.H., Massick, S.M.: Hadamard transform ion mobility spectrometry. Anal. Chem. 78(1), 44-51 (2006)

63. Gillig, K.J., Ruotolo, B.T., Stone, E.G., Russell, D.H.: An electrostatic focusing ion guide for ion mobility-mass spectrometry. Int. J. Mass Spectrom. 239(1), 43-49 (2004) 
64. Kwasnik, M., Fuhrer, K., Gonin, M., Barbeau, K., Fernandez, F.M.: Performance, resolving power, and radial ion distributions of a prototype nanoelectrospray ionization resistive glass atmospheric pressure ion mobility spectrometer. Anal. Chem. 79(20), 7782-7791 (2007)

65. Kwasnik, M., Caramore, J., Fernandez, F.M.: Digitally-multiplexed nanoelectrospray ionization atmospheric pressure drift tube ion mobility spectrometry. Anal. Chem. 81(4), 1587-1594 (2009)

66. Kurulugama, R.T., Nachtigall, F.M., Lee, S., Valentine, S.J., Clemmer, D.E.: Overtone mobility spectrometry. Part 1. Experimental observations. J. Am. Soc.Mass Spectrom 20(5), 729-737 (2009)

67. Merenbloom, S.I., Glaskin, R.S., Henson, Z.B., Clemmer, D.E.: Highresolution ion cyclotron mobility spectrometry. Anal. Chem. 81(4), 14821487 (2009)

68. Valentine, S.J., Stokes, S.T., Kurulugama, R.T., Nachtigall, F.M., Clemmer, D.E.: Overtone mobility spectrometry. Part 2. Theoretical considerations of resolving power. J. Am. Soc. Mass Spectrom. 20(5), 738750 (2009)

69. Revercomb, H.E., Mason, E.A.: Theory of plasma chromatography gaseous electrophoresis - review. Anal. Chem. 47(7), 970-983 (1975)

70. Siems, W.F., Wu, C., Tarver, E.E., Hill, H.H., Larsen, P.R., McMinn, D.G. Measuring the resolving power of ion mobility spectrometers. Anal. Chem. 66(23), 4195-4201 (1994)

71. Mason, E.A.M., McDaniel, E.W.: Transport properties of ions in gases Wiley, New York (1988)

72. Shvartsburg, A.A., Jarrold, M.F.: An exact hard-spheres scattering model for the mobilities of polyatomic ions. Chem. Phy. Lett. 261(1/2), 86-91 (1996)

73. Mesleh, M.F., Hunter, J.M., Shvartsburg, A.A., Schatz, G.C., Jarrold, M.F.: Structural information from ion mobility measurements: effects of the longrange potential. J. Phys. Chem. 100(40), 16082-16086 (1996)

74. Wyttenbach, T., vonHelden, G., Batka, J.J., Carlat, D., Bowers, M.T. Effect of the long-range potential on ion mobility measurements. J. Am. Soc. Mass Spectrom. 8(3), 275-282 (1997)

75. Harris, G.A., Fernandez, F.M.: Simulations and experimental investigation of atmospheric transport in an ambient metastable-induced chemical ionization source. Anal. Chem. 81(1), 322-329 (2009)

76. Kwasnik, M., Fernandez, F.M.: Theoretical and experimental study of the achievable separation power in resistive-glass atmospheric pressure ion mobility spectrometry. Rapid Commun. Mass Spectrom. 24(13), 19111918 (2010)

77. Glaskin, R.S., Valentine, S.J., Clemmer, D.E.: A scanning frequency mode for ion cyclotron mobility spectrometry. Anal. Chem. 82(19), 8266-8271 (2010)

78. Valentine, S.J., Kurulugama, R.T., Clemmer, D.E.: Overtone mobility spectrometry. Part 3. On the origin of peaks. J. Am. Soc. Mass Spectrom. 22(5), 804-816 (2011)

79. Siems, W.F., Viehland, L.A., Hill Jr., H.H.: Improved momentum-transfer theory for ion mobility. 1. Derivation of the fundamental equation. Anal. Chem 84(22), 9782-9791 (2012)

80. Stlouis, R.H., Hill, H.H.: Ion mobility spectrometry in analytical chemistry. Cri. Rev. Anal. Chem. 21(5), 321-355 (1990)
81. Clemmer, D.E., Jarrold, M.F.: Ion mobility measurements and their applications to clusters and biomolecules. J. Mass Spectrom. 32(6), 577-592 (1997)

82. Hoaglund-Hyzer, C.S., Counterman, A.E., Clemmer, D.E.: Anhydrous protein ions. Chem. Rev. 99(10), 3037-3079 (1999)

83. Collins, D.C., Lee, M.L.: Developments in ion mobility spectrometry-mass spectrometry. Anal. Bioanal. Chem. 372(1), 66-73 (2002)

84. Bohrer, B.C., Mererbloom, S.I., Koeniger, S.L., Hilderbrand, A.E., Clemmer, D.E.: Biomolecule analysis by ion mobility spectrometry. Ann. Rev. Anal. Chem. 1, 293-327 (2008)

85. Donohoe, G.C., Maleki, H.A.J.R., Khakinejad, M., Yi, J., McBride, C., Nurkiewicz, T.R., Valentine, S.J.: A new ion mobility-linear ion trap instrument for complex mixture analysis. Anal. Chem. 86(16), 8 (2014)

86. Tang, K., Shvartsburg, A.A., Lee, H.N., Prior, D.C., Buschbach, M.A., Li, F.M., Tolmachev, A.V., Anderson, G.A., Smith, R.D.: High-sensitivity ion mobility spectrometry/mass spectrometry using electrodynamic ion funnel interfaces. Anal. Chem. 77(10), 3330-3339 (2005)

87. Lee, S., Li, Z.Y., Valentine, S.J., Zucker, S.M., Webber, N., Reilly, J.P., Clemmer, D.E.: Extracted fragment ion mobility distributions: a new method for complex mixture analysis. Int. J. Mass Spectrom. 309, 154-160 (2012)

88. Shelimov, K.B., Jarrold, M.F.: Conformations, unfolding, and refolding of apomyoglobin in vacuum: an activation barrier for gas-phase protein folding. J. Am. Chem. Soc. 119(13), 2987-2994 (1997)

89. Shelimov, K.B., Clemmer, D.E., Hudgins, R.R., Jarrold, M.F.: Protein structure in vacuo: gas-phase confirmations of BPTI and cytochrome $c$. J. Am. Chem. Soc. 119(9), 2240-2248 (1997)

90. Valentine, S.J., Anderson, J.G., Ellington, A.D., Clemmer, D.E.: Disulfideintact and -reduced lysozyme in the gas phase: conformations and pathways of folding and unfolding. J. Phys. Chem. B 101(19), 3891-3900 (1997)

91. Available at: [http://www.iub.edu/ clemmer/Research/Cross $\% 20$ Section $\% 20$ Database/Proteins/protein cs.htm]. Accessed October 23, 2014

92. Evans, S.E., Lueck, N., Marzluff, E.M.: Gas phase hydrogen/deuterium exchange of proteins in an ion trap mass spectrometer. Int. J. Mass Spectrom. 222(1/3), 175-187 (2003)

93. Zhang, Z., Browne, S.J., Vachet, R.W.: Exploring salt bridge structures of gas-phase protein ions using multiple stages of electron transfer and collision induced dissociation. J. Am. Soc. Mass Spectrom. 25(4), 604-613 (2014)

94. Breuker, K., Bruschweiler, S., Tollinger, M.: Electrostatic stabilization of a native protein structure in the gas phase. Angew. Chem. Int. Ed. 50(4), 873877 (2011)

95. Prell, J.S., O'Brien, J.T., Steill, J.D., Oomens, J., Williams, E.R.: Structures of protonated dipeptides: the role of arginine in stabilizing salt bridges. J. Am. Chem. Soc. 131(32), 11442-11449 (2009)

96. Swaney, D.L., McAlister, G.C., Wirtala, M., Schwartz, J.C., Syka, J.E., Coon, J.J.: Supplemental activation method for high-efficiency electrontransfer dissociation of doubly protonated peptide precursors. Anal. Chem. 79(2), 477-485 (2007)

97. Cook, S.L., Jackson, G.P.: Metastable atom-activated dissociation mass spectrometry of phosphorylated and sulfonated peptides in negative ion mode. J. Am. Soc. Mass Spectrom. 22(6), 1088-1099 (2011) 